\title{
Comparing Speed Estimations from a Moving Vehicle in Different Traffic Scenarios: Absence versus Presence of Traffic Flow
}

\author{
Ángela Conchillo ${ }^{1}$, Miguel Ángel Recarte ${ }^{1}$, Luis Nunes ${ }^{2}$, and Trinidad Ruiz ${ }^{1}$ \\ ${ }^{1}$ Universidad Complutense de Madrid \\ ${ }^{2}$ Departamento de Investigación y Formación Vial. Dirección General de Tráfico. Madrid
}

\begin{abstract}
The aim of this research was to study the performance in a speed estimation task of a passenger travelling in a real car in different scenarios: a closed track used in previous experimental studies was compared with interurban traffic environment involving a secondary road and a highway. At the same time, the effect of sex and driving experience on speed estimation was analyzed. Thirty-six participants (18 male and 18 female, half of each group being drivers and half non-drivers) estimated the speed of the car in which they travelled as passengers. The actual speed values varied in the range of $40-100 \mathrm{~km} / \mathrm{h}$ for the secondary road, $70-120 \mathrm{~km} / \mathrm{h}$ for the highway condition, and $40-120 \mathrm{~km} / \mathrm{h}$ for the track. The results obtained for the track in previous studies (Recarte \& Nunes, 1996; Recarte, Conchillo, \& Nunes, 2004, 2005) were replicated in the same condition and were also verified for the secondary road scenario. However, a different pattern of errors was found for the highway. From the viewpoint of psychophysics, the participants were more accurate on the without-traffic track than in real traffic conditions, considered as a whole. The differences found between road and highway are discussed. No effect was found for between- subject variables, sex, and driving experience.
\end{abstract}

Keywords: speed estimation, subjective speed, traffic psychology

El objetivo de esta investigación es comparar las estimaciones de la velocidad de un coche real circulando en diferentes escenarios: un circuito sin tráfico, utilizado en estudios experimentales previos, se compara con un escenario interurbano abierto al tráfico, consistente en un tramo de carretera convencional y un tramo de autovía. Asimismo se analiza el efecto del sexo y la experiencia de conducción sobre las estimaciones de la velocidad. Treinta y seis participantes (mitad varones, mitad mujeres y, por experiencia, mitad conductores y mitad no conductores) estimaron la velocidad del coche en el que iban sentados como pasajeros. Las velocidades a estimar variaron de 40 a $100 \mathrm{~km} / \mathrm{h}$ en carretera, de 70 a $120 \mathrm{~km} / \mathrm{h}$ en autovía, y de 40 a $120 \mathrm{~km} / \mathrm{h}$ en el circuito. Los resultados obtenidos en circuito replicaron los de estudios previos (Recarte y Nunes, 1996; Recarte, Conchillo y Nunes, 2004; 2005), y también los obtenidos en carretera. Sin embargo, la estimación en autovía presentó un patrón de errores diferente a los anteriores. Desde el punto de vista de la psicofísica, los sujetos estimaron con más precisión en el circuito sin tráfico que en las dos condiciones de tráfico real, carretera y autovía, en su conjunto. Se comentan las diferencias entre carretera y autovía. No se encontraron diferencias debidas a las variables inter-sujetos, sexo y experiencia en conducción.

Palabras clave: estimación de la velocidad, velocidad subjetiva, psicología del tráfico

This research was funded by the Dirección General de Tráfico. Spain.

Correspondence concerning this article should be addressed to Ángela Conchillo, Facultad de Psicología. Universidad Complutense de Madrid. Campus de Somosaguas. 28223 - Madrid (Spain). e-mail: conchillo@ psi.ucm.es 
Ordinary driving implies a diversified attentional strategy in order to cope with the variety and amount of information to be processed: anticipating other users' behavior, checking road surface and trajectory, attending traffic signs or in-car displays, and speed control (or longitudinal control), involving adapting speed to traffic conditions such as headway keeping and controlling speed in accordance with traffic rules.

Such adaptation to speed limits imposes a certain amount of visual attention to check the speedometer, which also means a certain amount of times of "eyes off the road." Given the tradeoff between looking the external environment and checking the speedometer, speed awareness relies on a balance between objective control, based on speedometer inspection, and subjective control, based on speed estimation, which, in turn, is based on external visual, auditory, and propioceptive clues. This trade-off between objective and subjective control becomes more critical with increased visual demands of the outside world: complex traffic situations and scenarios (Nunes \& Recarte, 2005). Besides this, current driving also means sharing attention with secondary activity foreign to traffic, involving more or less visual and/or cognitive resources. The experimental evidence of a speedometer-inspection-reduction effect, produced by concurrent mental activity, found by Recarte and Nunes (2000, 2003), provides additional support to the assumption that, under increasingly demanding conditions, speed control tends to rely more on subjective estimation than on objective information. Consequently, the empirical study of subjective speed estimation while driving has a remarkable applied interest.

Many studies on speed perception have been carried out in simulated environments, and few in the real world. Simulated scenarios present methodological advantages to test some theoretical hypotheses, when considering application to road safety (e.g., speed- reduction measures, Comte \& Jamson, 2000; Godley, Triggs, \& Fildes, 2004). But the experimental demonstration of the equivalence of simulated conditions and reality is scarce and unconfirmed (Conchillo, Nunes, Ruiz, \& Recarte, 1999; Harms, 1996; Recarte, Conchillo, \& Nunes, 2005). A study explicitly focusing on the validation of a driving simulator for speed research (Godley, Triggs, \& Fildes, 2002) indicated positive results in terms of relative validity, regarding the evaluation of drivers' decelerating reactions to specific speed reduction measures, while at the same time, the authors remark on the lack of absolute validity when comparing speed values between real driving and simulated conditions, and the limited scope of the relative validity results.

Among studies performed in real driving conditions is Denton's (1966) research, where a subjective speed scale was obtained using a ratio method (doubling or halving). Evans (1970) and Ohta and Komatsu (1991) investigated the effect of suppression of auditory or visual information on speed perception. Triggs and Berenyi (1982) and Osaka (1988) studied speed estimation under daylight and nighttime conditions. Milosevic (1986), and Milosevic and Milic (1990) also used a real vehicle and an estimation method to study speed perception. Recarte and Nunes (1996) investigated the equivalence of estimation and production methods and the effect of driving experience, using an instrumented car. Recarte, Conchillo, and Nunes (1996, 2004) also studied the estimation of speed variations using a production method (increasing or reducing speed, either in absolute increments or in proportional terms, doubling or halving the speed). Also, Conchillo, Hernández, Recarte, and Nunes (2000), Conchillo, Hernández, Recarte, and Ruiz (2000), and Ruiz, Hernández, Conchillo, and Recarte (2001) focused on speed estimation from various other perspectives, such as the consistence of estimations, the psychophysical functions, and the dependence serial of the estimations.

Most of the above-mentioned studies were performed with real vehicles in the absence of traffic. An exception is the study by Triggs and Berenyi (1982), in which they performed the tests on a two-lane freeway with low traffic density. Concerning the need to prove the equivalence of experimental conditions and the real world, the issue of how speed estimation can be affected by the presence of other vehicles must also be addressed in order to determine the extent to which results obtained on a closed track can be generalized to real traffic conditions.

Considering the results of previously mentioned research, there is general agreement about the tendency to underestimate speed, within a variety of different magnitudes for the measured errors, depending on a diversity of experimental conditions. Recarte and Nunes (1996), and Recarte et al. (2004) proved the equivalence of the estimation and production methods and found a pattern of general underestimation and overproduction, and a reduction of error with increasing speed (from $-18.7 \mathrm{~km} / \mathrm{h}$ at a target speed of $60 \mathrm{~km} / \mathrm{h}$ to $-3.7 \mathrm{~km} / \mathrm{h}$ at $120 \mathrm{~km} / \mathrm{h}$ ). This effect of speed was also observed by Evans (1970) in the passenger condition. Ohta and Komatsu (1991) found that subjective (estimated) speed increased in a higher proportion than real speed (the exponent of the potential function was 1.5), although it is not possible to interpret the errors in terms of $\mathrm{km} / \mathrm{h}$, because they used an arbitrary scale. On the other hand, Triggs and Berenyi (1982), the only reported study performed in real environment with real traffic, found no systematic error reduction with increasing speed in any of the experimental conditions. Although this could be due to the different environmental conditions (presence vs. absence of traffic), this explanation is purely speculative, because the experimental design, type of car, and participants were different in each research.

The present research is an attempt to study directly the issue of the extent to which results obtained on a closed track in absence of traffic can be generalized to real traffic conditions. Consequently, we kept constant the car, the estimation method, the range of speed values, and the participants. The main independent variable was the scenario (closed track with no traffic vs. open road with normal traffic). As a secondary objective, in order to compare our results with those of Recarte and Nunes (1996), we also considered the variables sex and driving experience. 


\section{Method}

\section{Participants}

Thirty-six students, aged between 20 and 30, distributed in four groups by sex and driving experience, participated in the experiment. All of them had normal visual acuity, and were paid for their contribution.

\section{Experimental design}

Two between-subject variables, driving experience and sex, and two within-subject variables, scenario and speed, were manipulated. There were two levels of experience: drivers with more than two years of driving experience and non-drivers (without a driver's license). There were two scenarios: closed track and open road. We tested nine speed values, varying in increments of $10 \mathrm{~km} / \mathrm{h}$, covering the range from $40 \mathrm{~km} / \mathrm{h}$ to $120 \mathrm{~km} / \mathrm{h}$. The resulting experimental design is $2 \times 2 \times[2 \times 9]$ (Experience $(2) \times \operatorname{Sex}(2) \times$ [Scenario (2) $\times$ Speed (9)]).

In order to control the effect of increasing or decreasing speed of the estimations, two trials were established for each speed value in each scenario so that, in one case, the target speed would be reached after a deceleration process following a previous higher speed and, in the other case, the target speed would be reached after a previous acceleration process. In both cases, the target speed would be stabilized during 9 seconds after the previous acceleration or deceleration. In order to make conditions comparable to ordinary driving conditions and to obey legal speed limits $(100 \mathrm{~km} / \mathrm{h}$ for road, $120 \mathrm{~km} / \mathrm{h}$ for highway), the open road condition was distributed into two subscenarios. A conventional road and a highway were used so that the lower speed values (40, 50, and $60 \mathrm{~km} / \mathrm{h}$ ) were performed exclusively on the road, the medium speed values $(70,80,90$, and $100 \mathrm{~km} / \mathrm{h})$ were performed once on the road and once on the highway, and the highest speed values (110 and $120 \mathrm{~km} / \mathrm{h}$ ) were performed exclusively on the highway. The scenarios and the speed values were conveniently balanced. Prior to the performance of each set of estimation trials in each scenario, two standard stimuli were presented, consisting of the speeds of 70 and $100 \mathrm{~km} / \mathrm{h}$.

\section{Materials and Procedure}

An instrumented car provided with a recording system was used. The speed was recorded at $50 \mathrm{~Hz}$ to allow for detailed control of speed uniformity during the trials. More details of the system can be found in Nunes and Recarte (1997). The closed track was a circular ring with a radius of $455 \mathrm{~m}$ and length $2.859 \mathrm{~m}$, the same as used in the previous cited studies. The open road test was run near Madrid on highway A-1 and on a secondary road with low traffic density.

The participants were seated in the right front seat of the instrumented vehicle and were instructed about the estimation method. There were two experimenters: one drove the car and was trained to optimize the uniformity of the speed conditions while the other one controlled the recording system of the experimental vehicle. In each trial, the driver reached the target speed from a previous predefined value according to the design, then stabilized the speed during approximately 9 seconds, and then honked the horn. Then, the participant gave a verbal response estimating the speed of the car at that moment, while pressing a button at the same time. Before starting each set of trials, explicit information about two speed values (70 and $100 \mathrm{~km} / \mathrm{h}$ ) was provided to the participant. These standard stimuli were also balanced.

\section{Results and Discussion}

The results are presented in the following sections: analysis of the estimation errors and reliability of estimations.

Table 1

Means and Standard Deviations (in Brackets) in km/h of Estimation Errors by Scenario and Speed

\begin{tabular}{cccc}
\hline Speed & Closed Track & Open Road & Total \\
\hline 40 & $-4.43(12.07)$ & $-4.53(11.22)$ & $-4.48(11.61)$ \\
50 & $-5.15(12.37)$ & $-5.54(13.47)$ & $-5.35(12.87)$ \\
60 & $-2.98(13.73)$ & $-4.39(12.48)$ & $-3.69(13.09)$ \\
70 & $-0.20(11.60)$ & $-4.66(12.00)$ & $-2.43(11.97)$ \\
80 & $-2.36(13.53)$ & $-5.38(11.36)$ & $-3.87(12.54)$ \\
90 & $-1.68(11.38)$ & $-3.55(12.59)$ & $-2.61(11.99)$ \\
100 & $0.24(12.12)$ & $-3.79(12.24)$ & $-1.77(12.30)$ \\
110 & $-0.40(11.55)$ & $-9.83(11.15)$ & $-5.12(12.26)$ \\
120 & $-0.15(14.47)$ & $-8.94(11.95)$ & $-4.55(13.94)$ \\
\hline Total & $-1.90(12.64)$ & $-5.62(12.18)$ & $-3.76(12.54)$ \\
\hline
\end{tabular}




\section{Analysis of the Estimation Errors}

An ANOVA was performed for the variables Sex $\times$ Experience $\times($ Scenario $\times$ Speed $)$, considering estimation errors as the dependent variable. No statistically significant effect of speed was found, $F(8,256)=1.70, p=.10$, but a significant effect of scenario was observed, $F(1,32)=5.76$, $p=.02$, and also for the interaction Speed $\times$ Scenario, $F(4.30,256)=0.64, p=.005$, with a high power for this test, $1-\beta=.987(d f$ s were modified by Greenhouse-Geisser epsilon). No statistically significant effects were found for any of the between-subject variables, or for their interaction. This same lack of effect was found for the interactions of between-subject variables with within-subject variables. Table 1 and Figure 1 show the estimation errors as a function of scenario and speed.

A general pattern of underestimation was verified in both scenarios for all the speed values, which is in accordance with the results obtained by other authors (Conchillo et al., 1999; Evans, 1970; Milosevic, 1986; Recarte et al., 2004; Recarte \& Nunes, 1996; Triggs \& Berenyi, 1982). The mean error was close to zero $(-1.90 \mathrm{~km} / \mathrm{h})$ for the closed track and higher for the open road $(-5.62 \mathrm{~km} / \mathrm{h})$. The error was similar for all the speed values and the lack of a significant effect of speed can be seen. However, it is noteworthy that in the two scenarios, the tendency of errors was opposite: On the closed track, errors tended to decrease with increasing speeds (varying from $-5 \mathrm{~km} / \mathrm{h}$ to $0 \mathrm{~km} / \mathrm{h}$, approximately), whereas on the open road, errors tended to increase (from $-5 \mathrm{~km} / \mathrm{h}$ to $-9 \mathrm{~km} / \mathrm{h}$, approximately). This is because, considering both scenarios together, these differences are cancelled out. The tendency of errors on the closed track was the same as that found by Recarte and Nunes (1996), although, in our case, the magnitude of the error was lower. The mean error on the closed track was $-1.90 \mathrm{~km} / \mathrm{h}$ in the present research, whereas it was $-14.8 \mathrm{~km} / \mathrm{h}$ in Recarte and Nunes' (1996) study. The two experiments were equivalent, except for one condition: the previous presentation of two standard stimuli before the estimation task (in the experiment by Recarte and Nunes of 1996, there was no presentation

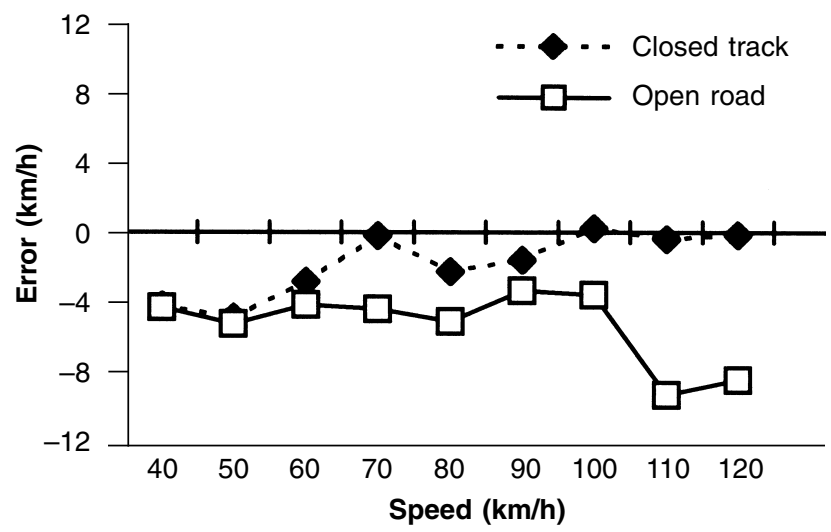

Figure 1. Estimation error for closed track and open road. of these stimuli). Therefore, it seems reasonable to conclude that, in the present experiment, the participants had more information and, as a consequence, were more accurate in their estimations.

Figure 2 shows the estimation errors in the open road scenario, splitting secondary road and highway. Considering secondary road and highway separately within the open road condition, one can observe that the tendencies of the error magnitude were quite similar, comparing road with closed track, and quite different when comparing secondary road with highway. On the secondary road, the mean error was slightly higher than on the closed track $(-3.64 \mathrm{~km} / \mathrm{h}$ versus $-1.90 \mathrm{~km} / \mathrm{h}$, respectively), and the tendency to reduce errors with increasing speed was quite similar in both scenarios. When comparing highway and secondary road, the mean error was higher in the first case than in the second $(-8.10$ $\mathrm{km} / \mathrm{h}$ versus $-3.64 \mathrm{~km} / \mathrm{h}$, respectively), and the tendencies were opposite with increasing speed: a reduced tendency on the secondary road and an increased tendency on the highway (from $-5.39 \mathrm{~km} / \mathrm{h}$ to $-8.94 \mathrm{~km} / \mathrm{h}$ for the highest speeds). We found no references in literature comparing speed estimations on road and highway. Triggs and Berenyi (1982), who used a real traffic scenario, considered two free lanes with very low traffic density, comparing day and nighttime conditions, which makes comparison of the results difficult.

The different pattern of errors between road and highway and the similarity between road and closed track leads us to hypothesize that the presence of parallel traffic flow, typical of highway environment, could explain this difference. Whereas traffic density on the road was relatively low (which was convenient for testing low values without great disturbance to other users), the highway tests were performed under medium traffic density, characterized by a continuous flow of vehicles, driving parallel to each other at various speeds in the other lane. Parallel traffic drastically modifies the optical flow-pattern of the moving scenario. Cars travelling in the same direction seem to have a higher potential of being considered additional clues to estimate one's own speed than do cars travelling in the opposite

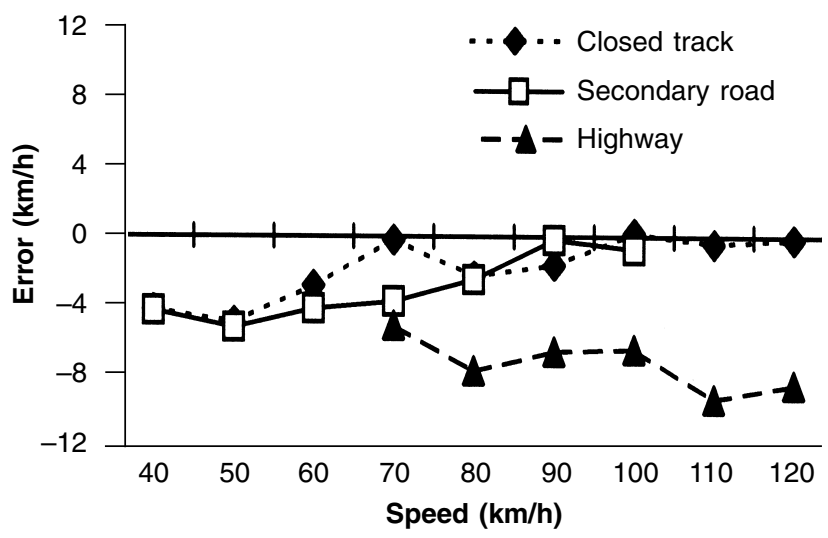

Figure 2. Estimation error for closed track, secondary road, and highway. 
direction, as on a conventional road. The assumptions made by the driver regarding other vehicles' speed, either faster or slower vehicles moving parallel to his or her vehicle, could influence and modify the estimation response compared to the simpler perceptual process that takes place in the solitude of a single lane on a conventional road or on a closed track. However, this is merely speculative. To test this hypothesis, it is necessary to compare speed estimations performed on highways with high and low traffic densities, and to manipulate and control the speeds of the other cars so as to test their potential influence on the driver's speed estimation.

Independently of the speculative nature of the above tentative explanation, the higher estimation error verified on the highway, considered as an empirical law, has practical implications: a higher probability of driver's unawareness of his or her own speed. In our study, at $120 \mathrm{Km} / \mathrm{h}$, the participants estimated their speed to be almost $10 \mathrm{~km} / \mathrm{h}$ lower.

On the other hand, Nunes and Recarte (2005) stress the strong weight of traffic complexity in terms of visual demands, and Recarte and Nunes $(2000,2003)$ demonstrate the reduction of speedometer inspection by increasing cognitive demands. Thus, considering the trade-off of attentional resources for speed control (proportion of time shared between speedometer inspection and glances at the road), our results predict that the higher probability of speed unawareness observed on the highway could also increase with increased traffic complexity, when the driver relies on subjective estimation, which is lower than actual driving speed.

Regarding the null effect of driving experience, this result is similar to those found in previous studies (Recarte et al., 2004; Recarte \& Nunes, 1996): The estimation task was carried out by drivers and non-drivers with identical accuracy; only in the speed production task, a small difference was found, namely, drivers produced target speed better than non-drivers, possibly due to their better training with the accelerator.

\section{Reliability of the Estimations}

Consistence of the participants' estimations is particularly interesting and that was analyzed in Conchillo, Hernández, Recarte, and Nunes (2000). Given that, for each speed, each participant performed two estimation trials, we used the split-half correlation as a measure of reliability. Reliability on the closed track was .92 , whereas on the open road scenario (road + highway), it was .88. Both correlation values were quite high, indicating that the individuals were highly consistent, which is in agreement with the results of Recarte and Nunes (1996), who obtained a correlation of .93 , although the method used to calculate the reliability was different. Regarding the between-subject variables, driving experience and sex, the reliability was .93 and .90 for drivers and non-drivers, respectively, and .91 for both sexes. Non-drivers did not seem to estimate speed with less certainty than did experienced drivers.

Summarizing, the results confirm the general pattern of speed underestimation, in accordance with the findings of previous research. On highways, the presence of traffic produced a tendency to increase the estimation errors. The tendency to reduce the errors' magnitude regarding speed was similar on the closed track and on the conventional road, in accordance with the pattern found by Conchillo et al. (1999), Recarte and Nunes (1996), and Recarte et al. (2004). The opposite pattern was observed on the highway, where the errors increased with higher speeds. Regarding to the applied value of this result, the deliberate omission of motivational factors in the present study (accepting that motivation and risk perception are crucial to explain speed violations) allowed us to focus on the occurrence of involuntary, perceptually induced, speed violations. Even assuming that a driver is positively motivated to comply with speed rules, the results allow us to predict a higher probability of relying on subjective estimation in more demanding conditions and, consequently, a higher probability of speed violations on highways, where higher estimation errors occur.

\section{References}

Comte, S.L., \& Jamson, A.H. (2000). Traditional and innovative measures for curves: An investigation of driver behaviour using a driving simulator. Safety Science, 36, 137-150.

Conchillo, A., Hernández, M.J., Recarte, M.A., \& Nunes, L.M. (2000). La estimación de la velocidad desde el punto de vista de la consistencia de los sujetos. Psicothema (Suppl. 2), 145151.

Conchillo, A., Hernández, M.J., Recarte, M.A., \& Ruiz, T. (2000). La psicofísica de la velocidad en el contexto de la conducción real de automóviles. Psicothema (Suppl. 2), 152-156.

Conchillo, A., Nunes, L.M., Ruiz, T., \& Recarte, M.A. (1999). Estimación de la velocidad de un automóvil mediante coche real e imágenes. Psicológica, 20, 1, 1-12.

Denton, G.G. (1966). A subjective scale of speed when driving a motor vehicle. Ergonomics, 9, 203-210.

Evans, L. (1970). Speed estimation for a moving automobile. Ergonomics, 13, 219- 230.

Godley, S.T., Triggs, T.J., \& Fildes, B.N. (2002). Driving simulator validation for speed research. Accident Analysis and Prevention, 34, 589-600.

Godley, S.T., Triggs, T.J., \& Fildes, B.N. (2004). Perceptual lane width, wide perceptual road centre markings and driving speeds. Ergonomics, 47, 237-256.

Harms, L. (1996). Driving performance on a real road and in a driving simulator: Result of a validation study. In A.G. Gale, I.D. Brown, C.M. Haslegrave, \& S.P. Taylor (Eds.), Vision in Vehicles $V$ (pp. 19-26). Amsterdam: Elsevier. 
Milosevic, S. (1986). Perception of vehicle speed. Revija za Psihologiju, 16, 11-19.

Milosevic, S., \& Milic, J. (1990). Speed perception in road curves. Journal of Safety Research, 21, 19-23.

Nunes, L.M., \& Recarte, M.A. (1997, April). Argos program: Development of technological systems and research programs for driver behavior analysis under real traffic conditions (ISHFRT 2). Proceedings of the International Seminar on Human Factors in Road Traffic 2. Universidade do Minho. Braga. Portugal.

Nunes, L.M., \& Recarte, M.A. (2005). Speed, traffic complexity, and visual performance: A study on open road. In G. Underwood (Ed.). Traffic and transport psychology: Theory and application (339-354). Amsterdam: Elsevier.

Ohta, H., \& Komatsu, H. (1991). Speed perception in drivingcomparison with TV observation. In A.G. Gale, I.D. Brown, \& C.M. Haslegrave ( Eds.), Vision in Vehicles III (pp. 415426). Amsterdam: Elsevier.

Osaka, N. (1988). Speed estimation through restricted visual field during driving in day and night: Nasotemporal hemisfield differences. In A.G. Gale, M.A. Freeman, \& C.M. Haslegrave (Eds.), Vision in Vehicles II ( pp. 45-55). Amsterdam: Elsevier.

Recarte, M.A., Conchillo, A., \& Nunes, L. (1996). Percepción y ajuste de incrementos de velocidad en automóvil. Psicológica, $17,441-454$.
Recarte, M.A., Conchillo, A., \& Nunes, L. (2004). Perception of speed and increments in cars. In T. Rothengatter, \& R.D. Huguenin (Eds.), Traffic and transport psychology: Theory and applications (pp.73-84). Amsterdam: Elsevier.

Recarte, M.A., Conchillo, A., \& Nunes, L. (2005). Estimation of arrival time in vehicle and video. Psicothema, 17, 112-117.

Recarte, M.A., \& Nunes, L. (1996). Perception of speed in an automobile: Estimation and production. Journal of Experimental Psychology: Applied, 2, 291-304.

Recarte, M.A., \& Nunes, L. (2000). Effects of verbal and spatial imagery task on eye fixations while driving. Journal Experimental Psychology: Applied, 6, 31-43.

Recarte, M.A., \& Nunes, L. (2003). Mental workload while driving: Effects on visual search, discrimination and decision making. Journal of Experimental Psychology: Applied, 9, 119-137.

Ruiz, T., Hernández, M.J., Conchillo, A., \& Recarte, M.A. (2001). Análisis del efecto secuencial en la estimación de la velocidad mediante modelos de regresión. Metodología de las Ciencias del Comportamiento, 3, 81-96.

Triggs, T., \& Berenyi, J.S. (1982). Estimation of automobile speed under day and night conditions. Human Factors, 24, 111-114.

Received, November, 18, 2005 Review received, February, 1, 2006 Accepted, February, 6, 2006 